\title{
Real-Time Warning Model of Highway Engineering Construction Safety Based on Internet of Things
}

\author{
Haoran Song, ${ }^{1}$ Hao Yu, ${ }^{2}$ Dianliang Xiao ${ }^{1 D},{ }^{1}$ and Yuexiang $\mathrm{Li}^{2}$ \\ ${ }^{1}$ Transportation Safety Research Center, China Academy of Transportation Science, Beijing 100029, China \\ ${ }^{2}$ Qilu Transportation Development Group, Jinan 250014, Shandong, China \\ Correspondence should be addressed to Dianliang Xiao; xiaodl@motcats.ac.cn
}

Received 8 October 2020; Revised 26 November 2020; Accepted 7 January 2021; Published 29 January 2021

Academic Editor: Sang-Bing Tsai

Copyright (c) 2021 Haoran Song et al. This is an open access article distributed under the Creative Commons Attribution License, which permits unrestricted use, distribution, and reproduction in any medium, provided the original work is properly cited.

Real-time and effective early warning of highway engineering construction sites is the key to ensuring the safety of highway engineering construction. At present, highway engineering construction safety early warning is limited by the experience of relevant personnel at the site and the dynamic changes of the project site environment. Therefore, the creation of a more active, smarter, and more effective real-time early warning model for construction safety is a strong complement to current research and has important theoretical and practical implications. The Internet of Things is the third wave of the information industry after computers, the Internet, and mobile communication networks. It is of great significance to promote the development of science and technology, economic growth, and social progress. Aiming at the shortcomings of the inadequate safety management methods for highway engineering construction in China, the inefficient efficiency of safety production supervision and management, and the emphasis on single and sporty supervision methods, a real-time early warning model for highway engineering construction safety based on the Internet of Things technology was constructed. By quantifying, scoring, and statistics of the safety situation during the construction process, the model achieves the goals of real-time monitoring, early warning, and handling hidden safety hazards. It overcomes problems such as untimely and unscientific safety issues in the past and effectively improves China's highway engineering construction. The experimental comparison between the real-time early warning model and the traditional early warning model in this paper shows that the accuracy of the early warning model proposed in this paper is improved by nearly $5 \%$, and the false alarm rate is reduced by nearly $4 \%$.

\section{Introduction}

With the rapid development of China's transportation construction, highway engineering construction projects are increasing day by day. At the same time, the situation of safety production in engineering construction is also very severe. Because highway engineering shows multiple points and long lines, many links, many parties, and long cycles, it has many cross-operations, many mechanical equipment, complex environments, large mobility of personnel, and many potential accidents. So no matter which part of the link is wrong, it may lead to a safety accident. Especially in recent years, highway engineering construction has gradually shifted to remote areas such as hills and mountains. The difficulty of construction has increased, hidden dangers have become increasingly prominent, and production safety tasks have become more onerous.

Internet of Things technology and building construction information technology have been used in civil engineering construction, such as radio frequency identification RFID technology, global positioning system (GPS), wireless sensor network, Zigbee, laser scanning technology, and handheld computer (PDA). At present, these frontier technologies are relatively lacking in theoretical research and engineering applications in the field of highway engineering construction safety management. The severe situation of highway engineering safety production in China should strengthen the research on the supervision model and countermeasures. Because illegal command, illegal operations, and labor discipline violations are the main factors that cause 
accidents, and the current supervision of construction safety is mostly limited to self-inspection, self-correction, and unannounced safety inspections, the "gust" supervision model lacks substantial management. Inadequate early warning processing resulted in the loss of a large amount of resources. Therefore, how to achieve "anytime, anywhere" safety supervision of the construction site with reasonable investment of funds and personnel and truly prevent the accidents in the construction of the project is an urgent problem.

In recent years, domestic and foreign researches on the application of the Internet of Things in accident early warning have been carried out. Security risk management has multiple characteristics and multiple targets, which has become a new field and an important development direction for the application of the Internet of Things. Cheng et al. [1] proposed a tunnel construction management monitoring system based on the Internet of Things. The system consists of a remote central control center, a main control unit, multiple data acquisition units, and a ZigBee terminal node. After the system is successfully initialized, the main control unit and data acquisition unit are connected to the remote central control center through the wireless network through manual or automatic mode and can also send control and query to obtain various sensor information commands of the monitoring system. The system mainly solves the problems of unstable electrical connection caused by wired communication, difficulty in wireless network connection, and high cost. Yanga et al. [2] analyzed the economic indicators of processing centers for urban road traffic problems, optimized dynamic traffic network allocation based on a continuous large-scale IoT input database, and proposed a high-performance computing model for dynamic traffic planning. This model is based on the performance of ultrahigh-performance computing. It is of great significance for real-time massive data and low-cost traffic network optimization planning and to promote the construction and development of smart cities. Luo et al. [3] established an emergency warning system for chemical parks based on the Internet in order to respond to environmental pollution accidents in chemical parks in a timely and effective manner. The operation of this system can effectively monitor the environmental quality of the entire park and its surroundings, prevent and timely control various environmental pollution accidents, and provide information support for park management. Jun et al. [4] designed monitoring and early warning and safety emergency systems for petrochemical enterprises due to incomplete monitoring, delay in accident warning, low emergency rescue efficiency, and incompatibility between monitoring systems and data sources. With this system, equipment can be monitored in real time. Equipment hazards and risks can also be analyzed automatically. This system helps petrochemical companies to achieve timely accident early warning and intelligent decision-making and scheduling of emergency rescue. In addition, it also solves the problem of incompatibility between different monitoring systems and data sources and improves the automation and intelligence level of safety production management and emergency command and dispatch of petrochemical enterprises.
This article uses advanced Internet of Things, information technology, and other technologies to warn you in a timely manner, find and eliminate hidden safety hazards and highways based on traditional early warning methods. Learn how to build a real-time early warning model for construction. Relying on the construction of highway engineering, through a comprehensive analysis of dangerous and harmful factors in the construction process of highway engineering, safety technical measures for construction preparation stage, roadbed engineering, and pavement engineering have been summarized. We have built a set of safety management and risk management systems for highway construction based on the Internet of Things technology. It is divided into three steps: analyzing early warning monitoring information, determining early warning levels, and accident response. With this system, traffic safety accidents can be realized. Early prevention and management, and for the first time, crisis management measures can be initiated. Highway Engineering Construction Safety Accident Early Warning Mechanisms can monitor the diagnosis of safety accidents, proactively control their occurrence, and replace accident handling with accident prevention. You can realize active safety management and improve the quality and efficiency of safety management work of highway engineering work.

\section{Proposed Method}

\subsection{Highway Engineering and Its Safety Management Theory}

2.1.1. Highway Engineering. Highway engineering [5-7] includes subgrade engineering, pavement engineering, bridge engineering, culvert engineering, tunnel engineering, drainage system engineering, safety structures, traffic safety engineering facilities, housing construction, greening, and mechanical and electrical engineering. The highway engineering safety management system is a relatively complex system consisting of several elements, each of which constitutes a closed-loop operating body. Any one element must maintain its own benign condition in order for the system to ensure a benign operation. However, this system is not static. With the continuous innovation and application of new technologies, new processes, and new management modes, the elements of the system will be continuously enriched, and the closed cycle body will continue to expand its connotation.

\subsubsection{Safety Management Theory of Highway Engineering.} The principles of highway engineering safety management mainly include safety system theory, safety cybernetics, safety information theory, accident prediction and prevention principles, and accident mutation theory. This article mainly introduces theories about accident prediction and prevention.

(1) Principle of Accident Prediction and Prevention. Accidents have the characteristics of causality, contingency, inevitability, and reproducibility. Accidents are a random phenomenon. The investigation of individual cases is uncertain, but for most 
accidents, it shows a certain law. According to the timeliness of prevention, the accident prevention model can be divided into two types: after-the-fact and predictive. The postevent model is to put rectification measures after an accident or disaster, mainly to avoid similar accidents; the forecast model is a proactive and proactive risk response strategy adopted before an accident or disaster. Including the five steps of formulating safety production goals, predicting safety production issues, finding key issues, preparing safety production plans, implementing safety production plans, evaluating safety production processes, and establishing new safety production goals.

(2) Accident Mutation Theory. Sudden change is a sudden change in the process of continuous development and the relationship between sudden changes and continuous changes. The occurrence of an accident can be understood as the sudden change of the system from a safe state to an accident state due to the qualitative change of the system caused by the continuous change of some parameters in the system. The human factor mainly refers to the safety education, management ability, physical fitness, resilience, and safety awareness of construction workers. The main factors include machine failure, construction conditions, safety protection devices, and the degree of mechanization in the construction process.

(3) Theory of Cause of Accident. The progress of science and technology has made people's understanding of accidents more and more profound, and they have a clearer understanding of the accidental and inevitability of accidents, especially the necessity of similar accidents. Therefore, we began to actively look for the law of incidents, analyze the characteristics of accidents, explore ways to find and eliminate accidents, and minimize the possibility of accidents as much as possible. The cause theory is to study and analyze a large number of accidents, make exhaustive discussions on the relationship between people, things, and the environment, and propose theories, methods, and strategies for preventing accidents. From domestic and foreign perspectives, experts and scholars have studied numerous accident occurrence rules and related theories are not exhaustive. The most representative of them are domino theory and comprehensive factor theory.

\subsection{Internet of Things}

2.2.1. Technical Framework of the Internet of Things. The general definition of the Internet of Things [8-10] is to use RFID, infrared sensors, GPS, laser scanners, and other information sensing devices to connect any item with the Internet according to agreed protocols for information exchange and communication to achieve a network of intelligent identification, positioning, tracking, monitoring, and management. Its technology system includes perception layer technology, network layer technology, application layer technology, and public technology. Figure 1 shows the technical architecture of the Internet of Things.

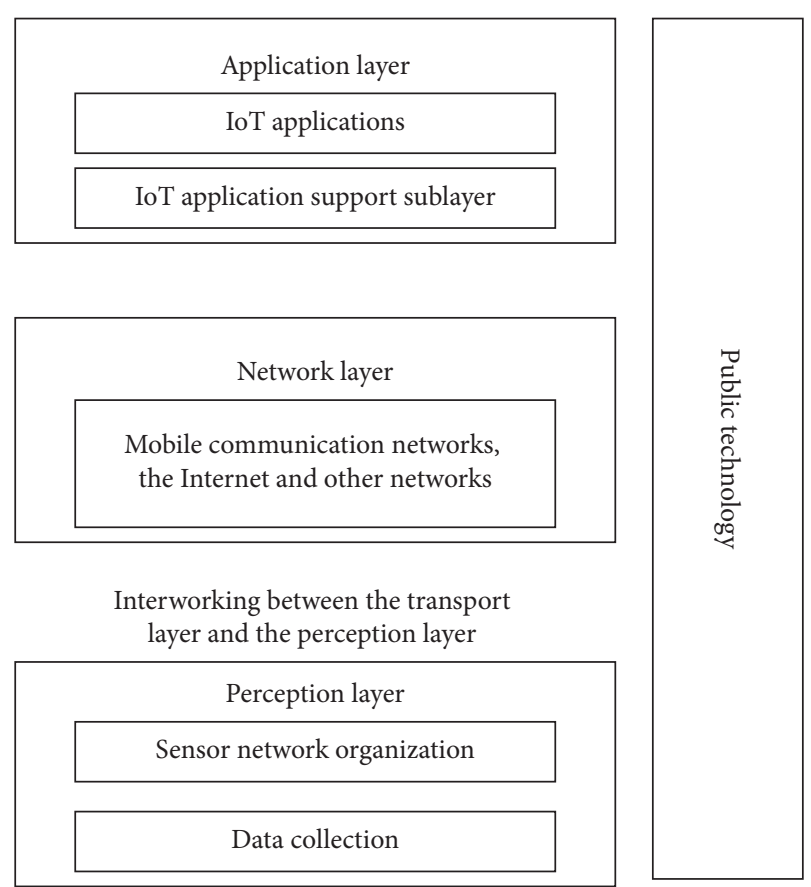

Figure 1: Technical system framework of the Internet of Things.

(1) Perception layer: data collection and perception are mainly used to collect physical events and data that occur in the physical world, including various physical quantities, identity, location information, audio, and video data. Data acquisition for the Internet of Things involves technologies such as sensors, RFID, multimedia information acquisition, two-dimensional code, and real-time positioning.

(2) Network layer: the network layer completes a wide range of information communication. It mainly uses existing WAN communication systems (such as PSTN networks, 2G/3G mobile networks, and the Internet) to quickly, reliably secure the information perceived by the perception layer. The ground is transmitted to various places on the earth, enabling the items to communicate over a long distance and a wide range.

(3) Application layer: the application layer completes the final interaction between the item and the person. The first two layers collect the information of the item on a large scale and summarize it in the application layer for unified analysis and decision-making. It is used to support cross-industry, cross-application, and crosssystem. The synergy, sharing, and intercommunication of information between them will improve the comprehensive utilization of information and serve humanity to the greatest extent.

(4) Public technology layer: the public technology layer does not belong to a specific level of the Internet of Things technology but has a relationship with the three layers of the Internet of things technology architecture. It includes identification and analysis, security technology, network management, and quality of service (QOS) management. 
2.3. Highway Construction Safety Early Warning Mechanism. In the absence of the application of the Internet of Things, the content of the Internet of Things depends on the development of existing industries, and the domestic industry information infrastructure is imperfect. Many companies are still lagging behind in comparison with Western developed countries. Therefore, the level of development of the domestic related industries' information infrastructure level, it is difficult to make new breakthroughs in the short term $[11,12]$. The specific applications of the Internet of Things have been seen in real life, such as remote antitheft, highway nonstop toll collection, smart library, and remote power meter reading, but these are only the shape of the Internet of Things technology and have not yet formed a huge Internet.

The research of safety early warning system is based on the enterprise early warning system theory. It is a new and creative research topic proposed for the contradiction that the safety production management level of construction enterprises is not suitable for the status of construction development. It analyzes and demonstrates the existing construction safety production mode, proposes a construction safety production early warning system that can monitor, diagnose, and precontrol safety accidents, and aims to provide a practical application value and operability for construction safety production management $[13,14]$. According to research and inspection of a large amount of relevant data, the research and practice of establishing a safety early warning system in the field of highway engineering construction is currently lagging behind, and for high-risk industries with frequent construction casualties every year, the establishment of relatively complete construction safety and early warning system, to further improve the level of safety management technology, is an urgent and arduous task, and it is also a new task at present $[15,16]$.

\subsubsection{Tasks of Research on Highway Construction Safety Early} Warning Mechanism. For highway engineering construction enterprises, the essence of construction safety production early warning management technology lies in advance control and prior management. The purpose is to realize early warning management in construction safety work, change the original tracking adjustment to the expected adjustment, and realize management thinking and management. The research on the safety early warning mechanism of highway construction engineering is to apply the occupational health and safety management system (OHSMS) to the daily safety management activities of construction enterprises and to determine the entire highway according to whether the processes and results of daily safety management activities meet the expected requirements of management objectives [17, 18]. The operation of the construction enterprise or a certain construction process is in an "accident state" or "normal state," and corresponding countermeasures are made accordingly. Throughout the entire management process, it is necessary to use high-tech to conduct early warning monitoring, replace accident handling with accident prevention, achieve hidden dangers as they are discovered and eliminated, and implement proactive safety management to continuously improve the level and level of safety management $[19,20]$. Here, we will study the early warning mechanism of highway construction accidents through hardware and software research. The hardware research refers to the analysis and evaluation of the safety status of the construction site through the establishment of an accident early warning monitoring platform, and the software research refers to the evaluation of the level of early warning through the establishment of a highway construction early warning model. These are two methods for early warning of accidents on highway construction sites.

\subsubsection{Main Functions of the Early Warning Mechanism for} Highway Construction Accidents. The establishment and operation of highway construction engineering accident warning mechanism has the following functions:

(1) Monitor and evaluate the safety accident environment: monitoring and evaluation of highway construction can better understand the impact of various environmental factors on safety and help take timely corresponding measures according to environmental changes that construction activities and machinery are facing, are about to face, and may face. In this process, the main goal is to complete the construction of the environmental monitoring and early warning system, scientifically select the location of the monitoring equipment, and timely and effectively transmit the monitoring information. For monitoring equipment with disaster prevention function, it is necessary to set a reference value so that it can accurately realize automatic alarm and ensure that information can be transmitted to each terminal in a timely manner when the operation control is lifted. In addition, changes in rainfall, river levels, etc., over time can also be displayed on the image, so weather conditions can be grasped more accurately [21, 22].

(2) Monitor and evaluate the safety status of construction machinery: that is to evaluate the use state of construction machinery and achieve precontrol, especially to ensure that special construction machinery is in a safe technical state.

(3) Monitor and evaluate construction personnel: that is, the behaviors of various types of personnel involved in highway construction and production in accordance with regulations and standard operating procedures.

(4) Monitor and evaluate safety management activities at all levels: this will clarify and improve the various systems and measures of construction safety management and evaluate the reliability status and operation trend of safety management activities.

(5) Monitor and evaluate emergency rescue measures in the event of a safety accident: the main purpose is to evaluate the emergency response plan that needs to be taken after the accident to minimize the accident 
losses. In order to achieve scientific, normal, and standardized handling of highway construction safety accidents and to better realize the above functions, the corresponding safety precontrol management indicators should be further improved to facilitate the smooth operation. The precontrol management mode for highway construction safety accidents is shown in Figure 2.

\subsubsection{Main Contents of Early Warning Research on Highway} Construction Engineering Accidents. The highway early warning mechanism realizes the early prevention and control of highway safety accidents and can initiate crisis management measures in the first time. Mainly, we must do three things: organizational preparation, daily monitoring, and crisis management:

(1) Organizational preparation is to establish an effective and effective organizational system required for precontrol management. Specifically, it includes the establishment of a precontrol management organization, clarification of the authority of different agencies and positions, determination of the operation mode of the agency, and preparation of a security accident crisis management plan.

(2) Daily monitoring refers to the special monitoring and evaluation of factors that may cause construction safety accidents. Its main content can be divided into two aspects of daily countermeasures and crisis simulation. Among them, the daily countermeasures are to avoid and correct the hidden dangers of safety accidents to ensure the normalization and orderly construction activities. The crisis simulation is to make assumptions and simulations of emergency rescues and expected disasters required for possible safety accidents and prepare for the countermeasures.

(3) Crisis management means that after encountering a construction safety accident, a predesigned emergency plan is started to deal with the accident in a timely and effective manner and quickly implement rescue. Therefore, highway construction safety early warning is mainly faced with three major tasks, namely, analysis of early warning monitoring information, determination of early warning levels, and taking accident handling measures.

Early warning monitoring analysis is to identify, analyze, and evaluate the factors that may cause highway construction safety accidents and make immediate warnings. Its main links are monitoring, identification and diagnosis. Monitoring is to monitor the factors that are most likely to induce highway construction safety accidents and pay attention to changes in the external environment, construction equipment operating conditions, and operating behaviors of operators at all times [23]. Identification is to analyze the monitoring information to find the main factors and catastrophic factors that may cause highway construction accidents. Diagnosis is a comprehensive analysis of the

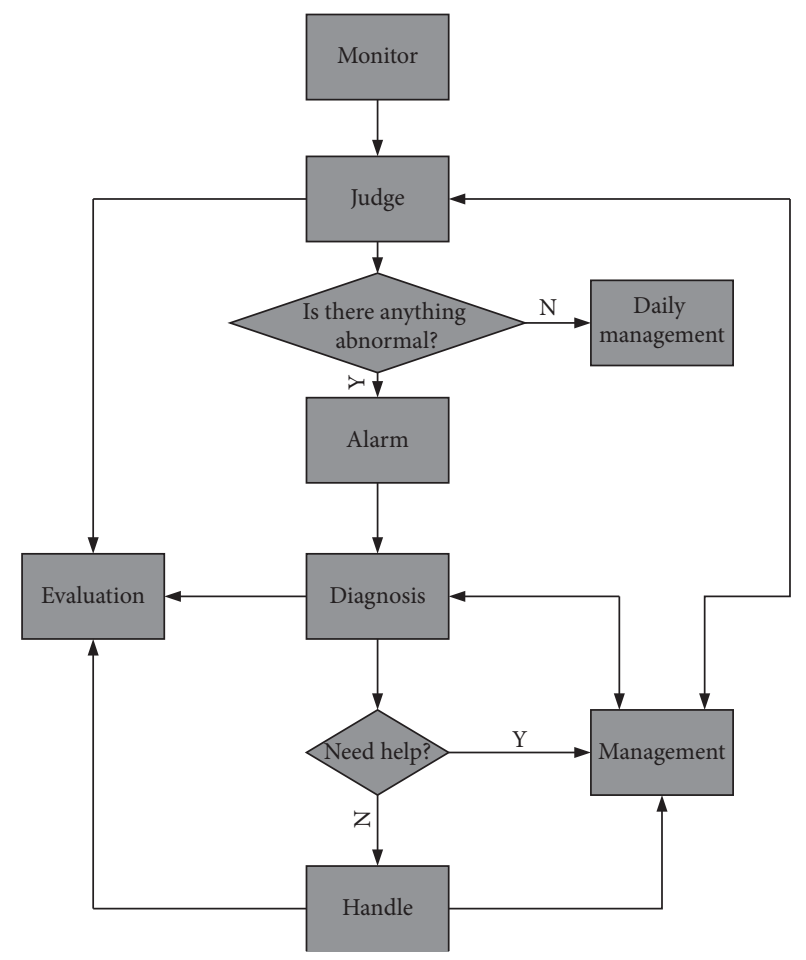

FIGURE 2: Flow chart of precontrol management of highway construction safety accidents.

identified causes of accidents, to find out the main influencing factors of accidents.

Early warning level evaluation is a method to define the early warning level of daily road construction accidents by analyzing and establishing an early warning analysis model. In order to establish a scientific and reasonable early warning indicator system, it is necessary to uniformly measure the importance of early level monitoring indicators at various levels, that is, to determine the weight of the monitoring indicators at each level. Here, the weight of each monitoring index is analyzed by AHP. Establish an evaluation standard and input relevant data for safety management of existing highway construction projects to assess the level of accident warning.

Accident emergency treatment refers to the timely and effective treatment and rescue of accidents in accordance with the emergency treatment plan designed and prepared in advance when a road construction safety accident occurs.

\subsection{Early Warning Model Construction}

2.4.1. Key Technical Systems for Highway Engineering Construction Safety Control. The causes of safety accidents in highway engineering construction are complex and diverse. The first problem is that the construction safety information collection, transmission, analysis, and processing are not timely and sufficient, and the final result image is insufficiently displayed.

The consequences of various disasters caused by highway engineering construction are serious and have a great impact on the social environment. During the construction process, it is urgent to provide real-time 
safety status analysis results according to the construction site conditions and can take construction control and emergency measures in a timely and effective manner. A security risk control system based on the Internet of Things technology for automatic monitoring before construction, tracking and positioning of personnel during construction, and real-time early warning is particularly urgent [24]. To this end, this article proposes highway engineering construction safety risk identification and early warning technology based on the Internet of Things technology and establishes a set of key technical systems for highway engineering construction safety control from risk identification, early warning to control, including preconstruction safety risk identification and prevention, construction. Relevant technologies are used to perceive, warn, and control moderate risks, so as to implement dynamic control of safety risks during the construction period of highway projects in complex environments. The security risk control system is shown in Figure 3.

2.4.2. Workflow of Early Warning System. After determining the work content of the safety production early warning system of the highway construction enterprise, the safety production early warning system of the construction enterprise will start to work according to the flow in Figure 4.

When the management instructions of the road construction enterprise safety production early warning management organization were issued, the construction enterprise safety production early warning management system began to operate. For highway construction enterprises, the safety production early warning system should operate as follows:

(1) The early warning agency monitors, diagnoses, and evaluates the safety production system and production process to identify the symptoms of accidents, to ensure that production is kept away from alert or crisis conditions, and to provide a reference for further prevention and control.

(2) If it is found that the enterprise has entered a crisis state and the enterprise has entered a safety management emergency procedure as a whole, an emergency management team must be established, and the early warning and supervision agencies shall jointly formulate emergency countermeasures and emergency plans, with responsibility to the people and scientific advancement. At this time, the functional safety management work is all under the responsibility of the emergency leadership team, and the enterprise's production safety management activities are also under the full responsibility of the emergency leadership team until the crisis is eliminated and safety production is fully restored.
(3) The early warning agency should also check the safety early warning work at all levels and have the responsibility for organizing, coordinating, and directing the work safety early warning and prevention work of the entire highway construction enterprise. For highway companies, the implementation of safety production early warning management is conducive to the establishment of a countermeasure database and can provide countermeasures for highway construction.

(4) The early warning department should also check the status of early warning work of safety management at all levels and be responsible for the organization of the early warning of the entire highway construction enterprise, the organization, coordination, and command of the precontrol work. The countermeasure database mainly includes two systems. The first is a system that summarizes, compares, and evaluates the existing successful countermeasures and failed countermeasures and mainly provides reference for future work. The second is a precontrol model countermeasure system, which is used for highway construction mainly to forecast the company's future production safety situation.

\section{Experiment}

The experiment in this article compares the real-time warning model based on the Internet of Things with the traditional warning model. This paper combines the NS-2 simulation method with the work process of the early warning system and analyzes and evaluates the early warning accuracy and false alarm rate of the real-time early warning model based on the Internet of Things. The construction monitoring road area is set to 800 meters $*$ 1000 meters, the simulation time is 1000 seconds, and 50 vehicle sensor nodes, 10 cluster head nodes, and 1 base station are randomly deployed. In the simulation, the vehicle sensor node and cluster head node are set to have the same transmit power and data communication radius. When data are transmitted on the Internet of Things, the channel rate is $1 \mathrm{Mbps}$, the propagation delay is $2 \mu \mathrm{s}$, the size of the encapsulated data packet is 8190 bits, the size of the control information data packet fed back by the base station is 400 bits, and the time warning phase is assumed to be 5 Stages. The warning distance in the space is 500 meters.

The highway engineering line is long; the terrain geology, hydrological conditions, site construction environment are complicated, the weather is harsh, and many obstacles may be encountered. Therefore, the requirements for electronic tags are higher, especially for its readwrite distance and antiinterference ability. Passive electronic tags are susceptible to interference, and the maximum read-write distance is $10 \mathrm{~m}$, which is not 


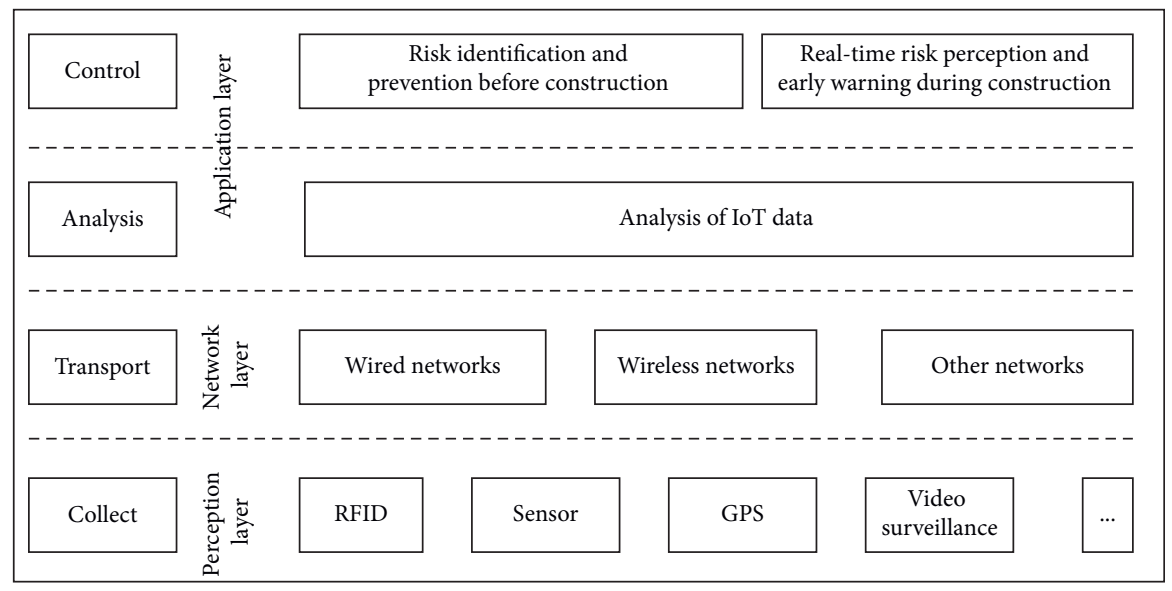

FIGURE 3: Highway engineering construction safety risk control system.

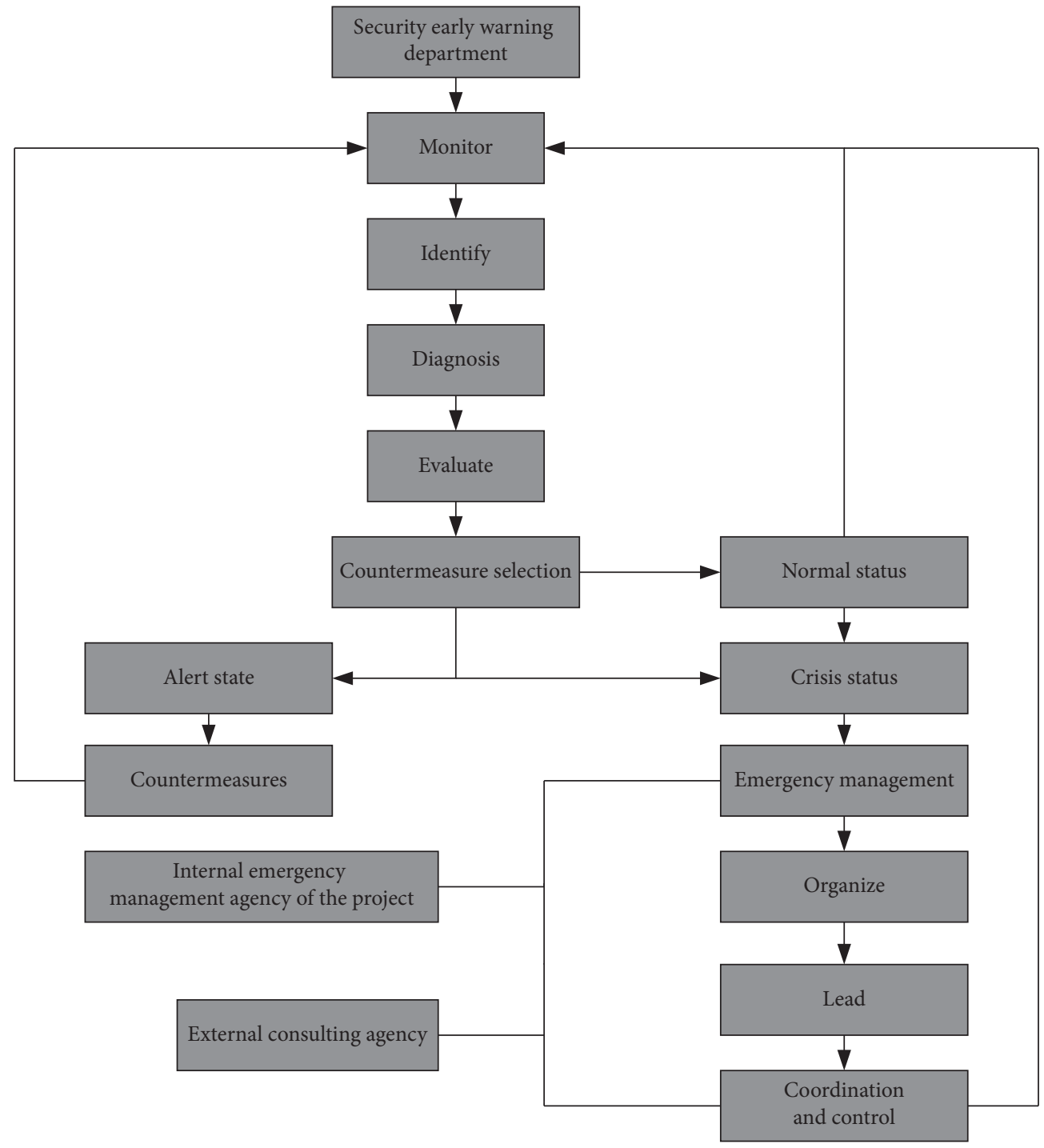

FIGURE 4: Work safety early warning system workflow. 
Table 1: Possibility of accident (L).

\begin{tabular}{lc}
\hline Point value & L \\
\hline 10 & Must happen \\
6 & Quite likely \\
3 & Possible, but not often \\
1 & Less likely \\
0.5 & Very unlikely \\
0.2 & Extremely unlikely \\
0.1 & Practically impossible \\
\hline
\end{tabular}

suitable for highway site construction needs. To cope with the shortcomings of passive electronic tags, active electronic tags are often used to sense the security situation. The maximum reading distance of the active electronic tag can reach $100 \mathrm{~m}$, and it has strong antiinterference ability. It uses its own radio frequency energy to send data to the reader and has strong adaptability to the complex construction environment of highway engineering. The system writes an electronic product code for each electronic tag, combining the electronic tag with construction tools and equipment. The reader antenna obtains the induced current, the electronic tag enters the reader signal range, the energy is activated, and it sends its own encoded information to the reader. It aggregates the data through the ZigBee sensor network, sends it to the frontend alarm unit, and sends relevant information to the alarm unit to determine the safety status of the project construction.

\section{Discussion}

4.1. Information Processing. After the system obtaining the information, it needs to be analyzed and processed, so as to more fully grasp the safety status of highway engineering construction. The front-end alarm unit uses cloud computer technology to perform distributed calculations on security conditions. After reading the tag information, query and decode the relevant information and analyze it to get the items represented by the tag. According to the factors such as item type and separation distance, the risk assessment is performed by the LEC method. Risk $R=L \times E \times C, R$ is the magnitude of risk, $L$ is the probability of an accident (values according to Table 1 ), and $E$ is the exposure of personnel. The frequency of accidents (values according to Table 2) $\mathrm{C}$ is the severity of the consequences of the accident (values according to Table 3 ). Based on the above values, the system calculates the results, evaluates the danger level, and automatically processes them (as shown in Table 4).

4.2. Performance Comparison. Figures 5 and 6 show the error performance curves of the model in this paper and the traditional model, which shows that the early warning model in this paper has faster convergence than traditional warning, which illustrates the real-time early warning model of highway construction safety based on the Internet of Things proposed in this paper. Figure 7 shows the early warning accuracy rates of the two early warning models
TABLE 2: How often people are exposed to hazardous environments (E).

\begin{tabular}{lc}
\hline Point value & E \\
\hline 10 & Continuous exposure \\
6 & Daily working hours exposed \\
3 & Once a week \\
2 & Once a month \\
1 & Several times a year \\
0.5 & Very rare \\
\hline
\end{tabular}

TABLE 3: The severity of the consequences of the accident (C).

\begin{tabular}{lc}
\hline Point value & C \\
\hline 100 & Catastrophe, many deaths \\
40 & Disaster, several deaths \\
15 & Very serious, 1 person died \\
7 & Severely disabled \\
3 & Severe injury \\
1 & Minor injury \\
\hline
\end{tabular}

TABle 4: Classification and treatment of danger levels (R).

\begin{tabular}{|c|c|c|}
\hline $\begin{array}{l}\text { Point } \\
\text { value }\end{array}$ & Degree of danger & Processing method \\
\hline$\geq 320$ & $\begin{array}{l}\text { Extremely dangerous to } \\
\text { continue working }\end{array}$ & $\begin{array}{l}\text { The alarm is immediately } \\
\text { issued through the front- }\end{array}$ \\
\hline $160-320$ & $\begin{array}{l}\text { Highly dangerous and } \\
\text { needs immediate } \\
\text { improvement }\end{array}$ & $\begin{array}{l}\text { end alarm, and the owner, } \\
\text { supervision, and } \\
\text { construction unit are }\end{array}$ \\
\hline $70-160$ & $\begin{array}{l}\text { Significantly dangerous } \\
\text { and needs improvement }\end{array}$ & $\begin{array}{c}\text { notified via SMS at the same } \\
\text { time, and recorded to the } \\
\text { background server }\end{array}$ \\
\hline $20-70$ & $\begin{array}{l}\text { More dangerous, need } \\
\text { attention }\end{array}$ & Immediate alarm via front \\
\hline$\geq 20$ & $\begin{array}{l}\text { Slightly dangerous and } \\
\text { acceptable }\end{array}$ & \\
\hline
\end{tabular}

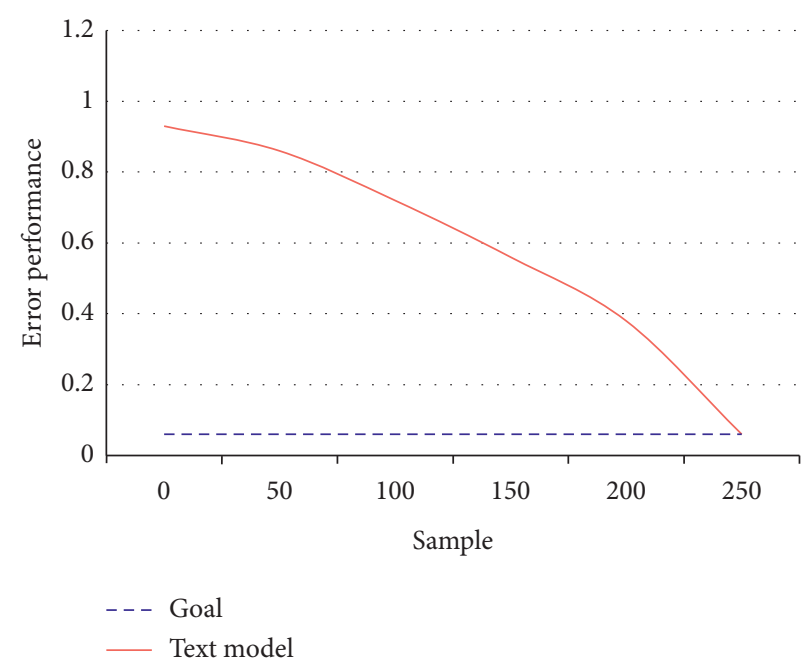

FIGURE 5: Error performance curve of the early warning model in this paper. 


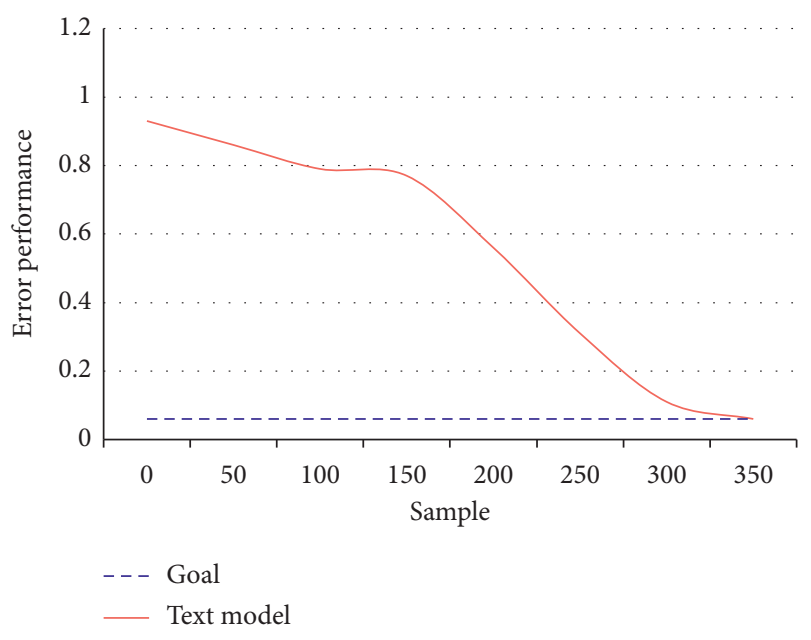

Figure 6: Error performance curve of traditional model.

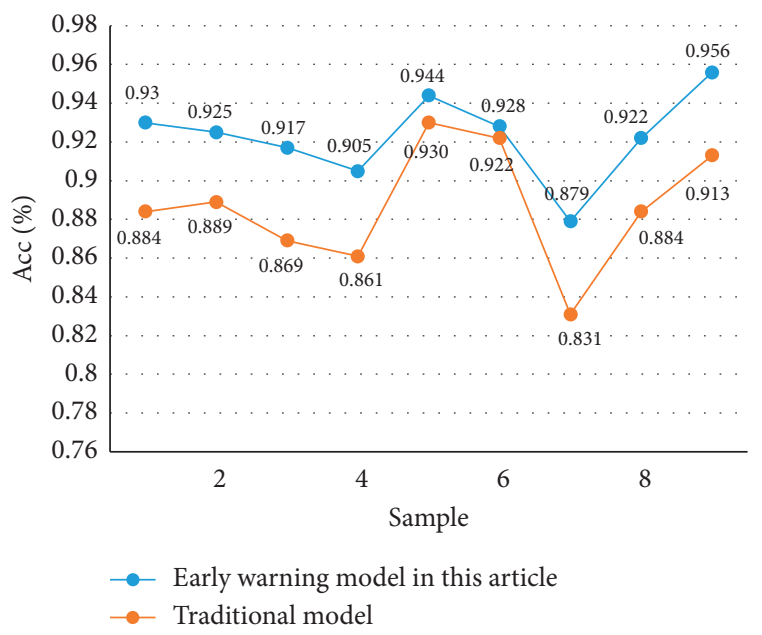

FiguRE 7: Early warning accuracy comparison.

under different sample sets. Experiments show that the accuracy rate of this model is nearly $5 \%$ higher than the traditional early warning model, and the false alarm rate is reduced by nearly $4 \%$.

\section{Conclusions}

Highway engineering has a long construction period, a complex construction environment, many cross-operations, and great potential safety hazards. If effective management measures are neglected, safety accidents may occur, resulting in large property losses and even serious casualties. To prevent safety accidents, it is necessary to take effective safety supervision measures. Although many units focus on self-inspection and self-correction, and increase safety supervision, the results achieved are not satisfactory. Early warning processing is not in place, and a lot of manpower and material resources may be wasted. Therefore, under the limited manpower and financial arrangements, timely and effective safety supervision of the construction site and the effective prevention of safety accidents are important goals of the construction unit.
The Internet of Things technology can track, monitor, and manage in real time, and it is applied to the safety management of highway engineering construction. It can overcome the shortcomings of traditional safety management methods, can promptly warn, find, and eliminate hidden safety hazards, and ensure the safety of highway engineering construction. This paper proposes a real-time early warning model for highway construction safety based on the Internet of Things and suggests that the model can be combined with wireless monitoring technology to further improve the real-time and early warning accuracy of the model.

The intelligent monitoring system is applied to the safety management of highway engineering construction, which not only meets the needs of safety management, but also tracks and early warns the safety protection facilities of construction workers on-site. It can detect and deal with the potential safety hazards as early as possible, eliminate the safety accidents in the bud state, minimize the possible losses caused by various risks, and achieve effective control of highway construction safety accidents. And it can ensure that the construction of the project is safe, smooth, and stable, reduce unnecessary losses, and help improve the efficiency of the project. At the same time, the system also plays a positive role in promoting the modernization, informationization, and intelligentization of highway engineering construction safety management. Therefore, it is worth popularizing and applying this intelligent supervision system in the safety management work of similar highway projects.

\section{Data Availability}

No data were used to support this study.

\section{Conflicts of Interest}

The authors declare that they have no conflicts of interest.

\section{Acknowledgments}

This work was supported by National Key R\&D Program of China (No. 2017YFC0805303).

\section{References}

[1] H. Cheng, N. Wu, and J. Lian, "The management and monitor system of tunnel construction based on internet of things," Proceedings of the Second International Conference on Mechatronics and Automatic Control, vol. 334, no. 12, pp. 1019-1026, 2015.

[2] J. Yanga, Y. Hana, and Y. Wanga, "Optimization of real-time traffic network assignment based on IoT data using DBN and clustering model in smart city," Future Generation Computer Systems, vol. 21, no. 15, pp. 147-154, 2017.

[3] G. Luo and H. Zhou, "Study on the chemical industrial park environmental pre-warning and emergency response system based on internet of things technology," Environmental Science \& Technology, vol. 6, no. 2, pp. 54-60, 2015.

[4] Z. Jun, L. V. Yun-Rong, Z. Jian-Xin et al., "Monitoringforewarning and safety emergency system for petrochemical 
industry based on internet of things," Modern Chemical Industry, vol. 8, no. 3, pp. 70-76, 2016.

[5] C. Tague, "Simulating the impact of road construction and forest harvesting on hydrologic response," Earth Surface Processes \& Landforms, vol. 26, no. 2, pp. 135-151, 2015.

[6] J. Lehne, N. S. Jacob and V. E. Oliver, "Building connections: political corruption and road construction in India," Journal of Development Economics, vol. 131, no. 12, pp. 124-132, 2018.

[7] V. J. Ferreira, V. Aitana Saez de Guinoa, T. García-Armingol et al., "Evaluation of the steel slag incorporation as coarse aggregate for road construction: technical requirements and environmental impact assessment," Journal of Cleaner Production, vol. 130, no. 1, pp. 175-186, 2015.

[8] S. Sicari, A. Rizzardi, L. A. Grieco, and A. Coen-Porisini, "Security, privacy and trust in Internet of Things: the road ahead," Computer Networks, vol. 76, no. 3, pp. 146-164, 2015.

[9] S. Li, L. L. Xu, D. Xu, and S. Zhao, "The internet of things: a survey," Information Systems Frontiers, vol. 17, no. 2, pp. 243-259, 2015.

[10] A. Al-Fuqaha, M. Guizani, M. Mohammadi, A. Mohammed, and A. Moussa, "Internet of things: a survey on enabling technologies, protocols and applications," Institute of Electrical and Electronics Engineers Communications Surveys \& Tutorials, vol. 17, no. 4, pp. 25-38, 2015.

[11] K. G. Srinivasa, A. Shikhar, J. S. Naveen, and B. J. Sowmya, "Social impacts of using internet of things and data analytics to prevent and reduce the rate of accidents," International Journal of Applied Evolutionary Computation, vol. 7, no. 4, pp. 60-76, 2016.

[12] C. Tang and N. Yang, "A monitoring and control system of agricultural environmental data based on the internet of things," Journal of Computational and Theoretical Nanoscience, vol. 42, no. 2, pp. 45-52, 2016.

[13] E. C. Eze, S. Zhang, E. Liu, E. N. Nweso, and J. C. Eze, "Timely and reliable packets delivery over internet of vehicles for road accidents prevention: a cross-layer approach," IET Networks, vol. 5, no. 5, pp. 127-135, 2016.

[14] J. J. Yang, B. Dong, and Z. Wang, "Research on the rabbit farm environmental monitoring and early warning system based on the internet of things," Journal of Computational \& Theoretical Nanoscience, vol. 16, no. 9, pp. 136-144, 2016.

[15] C. Dashora, P. Edwin Sudhagar, and J. Marietta, "IoT based framework for the detection of vehicle accident," Cluster Computing, vol. 23, no. 2, pp. 1-16, 2019.

[16] H. Lu, X. Zhang, and B. Li, "Design and application of highrisk pregnancy monitoring \& warning internet platform based on internet of things," Chinese Journal of Medical Instrumentation, vol. 41, no. 5, pp. 327-329, 2017.

[17] N. Jan and N. Olson, "The internet of things and convenience," Internet Research, vol. 26, no. 2, pp. 360-376, 2016.

[18] G. Panorios, "Benardos, george christopher vosniakos. Internet of things and industrial applications for precision machining," Solid State Phenomena, vol. 261, no. 1, pp. 440-447, 2017.

[19] A. Palade, C. Cabrera, and L. Fan, "Middleware for internet of things: an evaluation in a small-scale IoT environment," Journal of Reliable Intelligent Environments, vol. 4, pp. 1-21, 2018.

[20] C. Perera, C. H. Liu, and S. Jayawardena, "The emerging internet of things marketplace from an industrial perspective: a survey," Institute of Electrical and Electronics Engineers Transactions on Emerging Topics in Computing, vol. 3, no. 4, pp. 585-598, 2015.
[21] K. G. Srinivasa, B. J. Sowmya, A. Shikhar, R. Utkarsha, and A. Singh, "Data analytics assisted internet of things towards building intelligent healthcare monitoring systems: iot for healthcare," Journal of Organizational and End User Computing, vol. 30, no. 4, pp. 83-103, 2018.

[22] S. K. Biswas, D. Devi, and M. Chakraborty, "A hybrid case based reasoning model for classification in internet of things (iot) environment," Journal of Organizational and End User Computing, vol. 30, no. 4, pp. 104-122, 2018.

[23] M. R. Reddy, K. G. Srinivasa, and B. E. Reddy, "Smart vehicular system based on the internet of things," Journal of Organizational and End User Computing, vol. 30, no. 3, pp. 45-62, 2018.

[24] R. Parada, J. Melià-Seguí, and R. Pous, "Anomaly detection using rfid-based information management in an iot context," Journal of Organizational and End User Computing, vol. 30, no. 3, pp. 1-23, 2018. 